\title{
Penerapan Model Persamaan Struktural pada Faktor-Faktor yang Berpengaruh terhadap Loyalitas Konsumen Pasar Swalayan
}

\author{
Oki Dwipurwani, Ning Eliyati \\ Jurusan Matematika, Fakultas MIPA, Universitas Sriwijaya \\ Jl. Raya Palembang - Prabumulih KM 32, Ogan Ilir Inderalaya 30662 \\ Email: okidwip@yahoo.com,ningeliyati@gmail.com
}

\begin{abstract}
ABSTRAK
Tujuan penelitian ini adalah untuk mengetahui faktor-faktor yang berpengaruh secara signifikan terhadap loyalitas konsumen pasar swalayan di Kota Palembang dan Kabupaten Ogan Ilir, Sumatera Selatan. Metode yang digunakan adalah Model Persamaan Struktural (MPS), karena peubah yang terlibat berupa peubah laten dan hubungan antara peubahnya bersifat langsung dan tak langsung. Hasil yang diperoleh adalah faktor kualitas harga memberikan pengaruh langsung terbesar secara signifikan terhadap kepuasan konsumen sebesar 0,51 dengan nilai statistik uji- $t$ sebesar 5,91. Faktor kepuasan konsumen memberikan pengaruh total terbesar terhadap loyalitas konsumen sebesar 0,89 dengan nilai statistik uji- $t$ nya sebesar 3,31 .
\end{abstract}

Kata kunci: Model Persamaan Struktural (MPS), Kepuasan dan loyalitas konsumen.

\section{ABSTRACT}

The aim of this research is to know factors having an influence by significant to self-service market consumer loyality in Palembang Town and Ogan Ilir Sub-Province, South Sumatra. There used a Structural Equation Models (SEM) analysis method, because variables in this research in the form of laten variable and causal relationship between a set of variables nor modestly, there is direct and indirectly relationship. The result show that price quality factor give biggest direct influence by significant to satisfaction of consumer equal to 0,51 with $t$-test statistical value equal to 5,91. The satisfaction of consumer have the biggest direct influence to the loyality of consumer equal to 0,89 with $t$-test statistical value equal to 3,31 .

Keywords:Structural Equation Models (SEM), Satisfaction and Loyality of Consumer

\section{Pendahuluan}

Makin pesatnya perkembangan bisnis pasar modern Indonesia, khususnya di Provinsi Sumatera Selatan, ditandai dengan munculnya berbagai pusat perbelanjaan seperti minimarket dan pasar swalayan. Keberadaan pasar swalayan ini menjangkau ke berbagai pelosok daerah dan mampu menekan keberadaan pasar tradisional yang ada di sekitarnya, contohnya pasar swalayan Indomaret dan Alfamart yang sedang gencar dalam mengembangkan gerai bisnisnya.

Agar mampu terus bersaing dan menjadi pilihan masyarakat dalam berbelanja, pihak pasar swalayan perlu terus menarik konsumen dan memberi kepuasan, serta menciptakan loyalitas konsumen. Loyalitas merupakan faktor penting dalam menunjang kemampuan bertahan hidup sebuah bisnis dan membantu menentukan kesuksesannya. Oleh karena itu perlu mengetahui faktor apa saja yang mempengaruhi loyalitas konsumen agar bisa mempertahankan keberadaannya, khususnya bagi pasar swalayan di Provinsi Sumatera Selatan.Faktor yang berpengaruh dapat diantaranya kualitas produk, kualitas harga, kualitas karyawan dan kualitas lokasi pasar swalayan. Kualitas produk dapat dilihat dari persepsi konsumen terhadap kemasan, kondisi, variasi, kelengkapan dan kesegaran produk yang pasarkan. Faktor kualitas harga dapat berupa kewajaran dan keekonomisan harga yang ditawarkan.Faktor kualitas karyawan dapat berupa interaksi karyawan pasar swalayan dengan konsumen. dan Faktor kualitas lokasi adalah mudah tidaknya pasar swalayan dijangkau oleh konsumen. 
Salah satu metode yang dapat mengakomodasi masalah ini adalah analisis jalur atau Model persamaan struktural (MPS), karena peubah-peubah yang terlibat bersifat laten, dan hubungan antara peubahnya bersifat langsung dan tidak langsung.

\section{Metode Penelitian}

Metode yang dilakukan berdasarkan langkah-langkah berikut.

\subsection{Menentukan peubah-peubah laten dan indikator yang terlibat.}

Untuk menentukan peubah laten dan indikator yang terlibat, lihat Tabel 1. Kemudian mendisain MPS secara teoritis hubungan antar peubah-peubah tersebut.

Tabel 1. Peubah Indikator, peubah laten dan simbolnya.

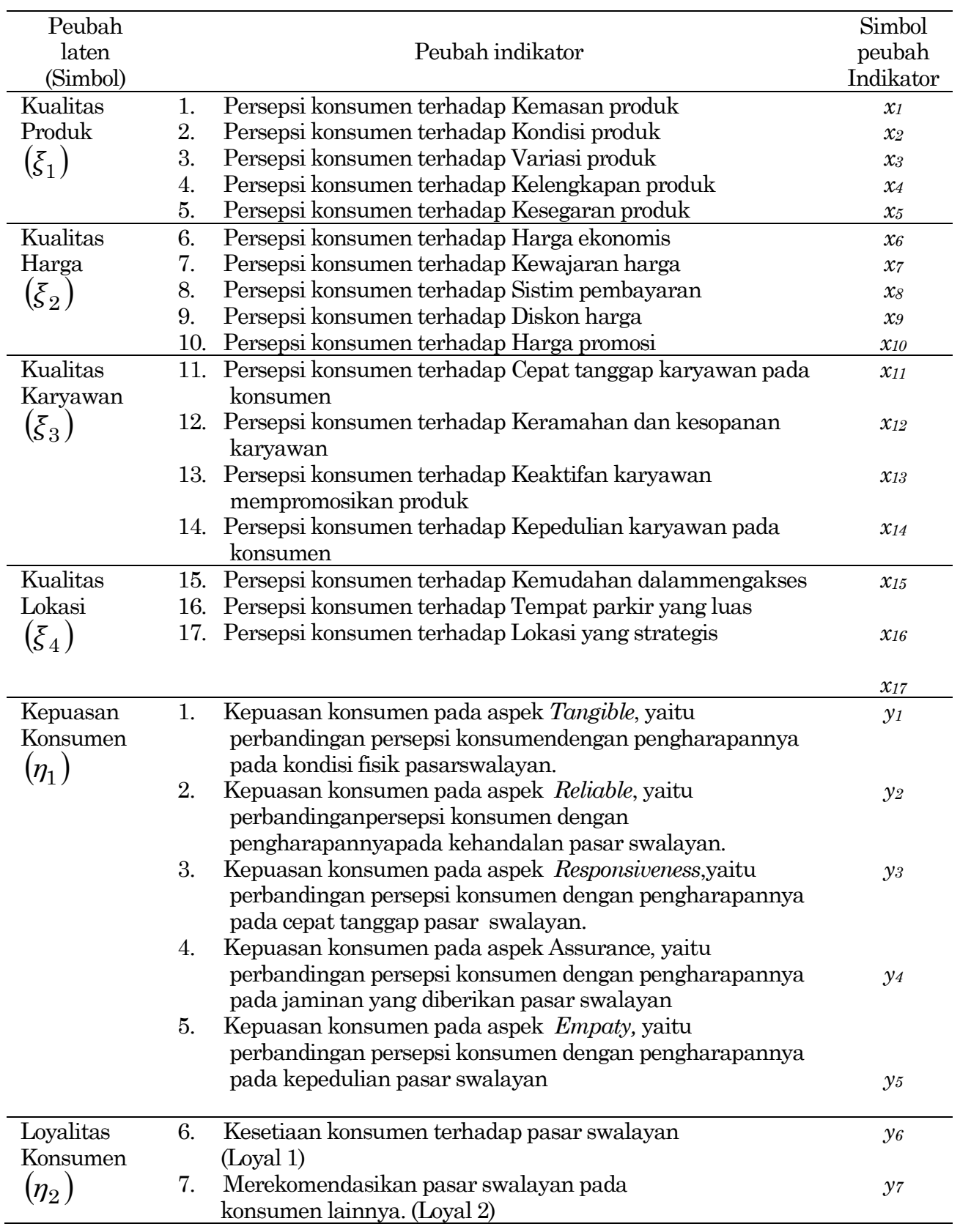




\subsection{Memperoleh data penelitian}

Data yang digunakan adalah data primer yang diperoleh melalui penyebaran koesioner. Jawaban pada koesioner memiliki skala likert dari 1 sampai 5. Pertanyaan dalam koesioner berupa pernyataan-pernyataan yang dievaluasi oleh responden. Responden pada penelitian ini adalah konsumen atau pengunjung pasar swalayan.

Pengambilan contoh menggunakan metode sampling bertingkat, diawali dengan memilih kecamatan sebagai contoh (sampel) dengan metode sampling klaster, kemudian menggunakan metode sampling acak proporsional dalam memilih pasar-pasar swalayan pada setiap kecamatan, selanjutnya menggunakan metode sampling purposive pada pemilihan responden. Setelah itu melakukan entri data hasil koesioner kedalam tabel dengan kolom-kolom objek dan nilai dari pertanyaan-pertanyaan koesioner. Data hasil koesioner ditransformasi menggunakan metode Succesive interval, sehingga skala pengukuran data menjadi interval dan menyebar normal.Kemudian menghitung nilai peubahpeubah indikator $x_{1}, \ldots, x_{17}$, dan $y_{1}, \ldots, y_{7}$.

\subsection{Melakukan prosedur analisis MPS}

Prosedur MPS dapat dilihat pada bagan alir Gambar 1.

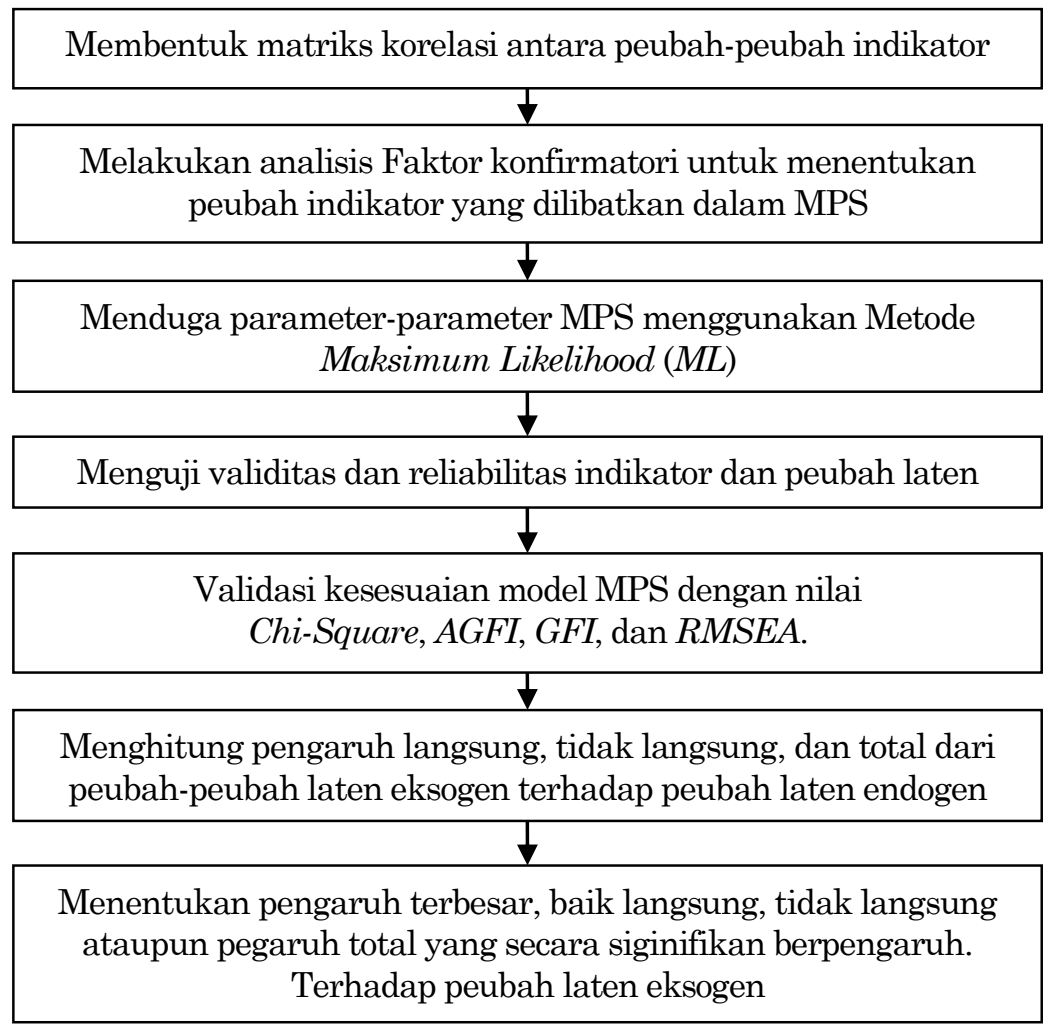

Gambar 1. Bagan alir prosedur analisis MPS

\section{Hasil dan Pembahasan}

\subsection{Kepuasan dan Loyalitas.}

Kepuasan suatu produk barang ataupun jasa, menurut (Zeithaml et al [9], Sutanto [7]), terbagi atas 5 (lima) dimensi, yaitu: Tangible (Kenyataan), Reliable (Kehandalan/dapat dipercaya), Responsiveness (Kecepatan Tanggap), Assurance (Jaminan) dan Empathy (Kepedulian). Kepuasan merupakan sebuah fungsi persepsi terhadap suatu produk barang atau jasa dan pengharapannya 
terhadap performance produk atau jasa tersebut, (Afiudin, [1]). Sementara itu, loyalitas bisa terbentuk apabila pelanggan merasa puas dengan tingkat layanan yang diterima, dan berniat untuk terus melanjutkan hubungan, (Fornell dalam Harun, [5]). Dalam penelitian ini, produk yang ditawarkan adalah produk Pasar Swalayan.

\subsection{Model Persamaan Struktural (MPS)}

Model Persamaan struktural (MPS) dengan peubah laten menggabungkan model pengukuran dan model jalur. Model persamaaan strukturalnya adalah sebagai berikut,

$$
\eta=\mathbf{\Gamma}+\mathbf{B} \eta+\zeta
$$

dimana $\eta$ : vektor endogen, $\xi:$ vektor peubah eksogen, B : matriks koefisien dari pengaruh peubah endogen terhadap peubah endogen lainnya, $\Gamma$ : matriks koefisien dari pengaruh peubah eksogen terhadap peubah endogen, $\zeta$ : vektor galat pada model jalur, $\eta$ dan $\xi$ berupa peubah-peubah tidak terukur atau peubah laten. Selanjutnya

$$
\begin{aligned}
& y=\Lambda^{y} \eta+\varepsilon \\
& x=\Lambda^{x} \xi+\delta
\end{aligned}
$$

dimana $y$ adalah vektor peubah peubah indikator bagi peubah laten $\eta, x$ adalah vektor peubah indikator bagi peubah laten $\xi, \Lambda^{y}$ adalah matriks koefisien regresi antara $y$, dengan $\eta, \Lambda^{x}$ adalah matriks koefisien regresi antara $x$ dengan $\xi, \varepsilon$ adalah vektor galat pada model pengukuran $y$ dan $\delta$ adalah vektor galat pada model pengukuran $y$, (Bolen [5]).

Metode untuk pendugaan parameter model pada penelitian ini menggunakan Metode Kemungkinan Maksimum (Maximum Likelihood : $M L$ ), yaitu metode yang meminimumkan fungsi pengepasan secara iteratif, dengan bentuk fungsi pengepasan metode $M L$ adalah sebagai berikut

$$
F_{M L}=\log |\hat{\mathbf{\Sigma}}|+\operatorname{tr}\left\{\mathbf{S} \hat{\mathbf{\Sigma}}^{-1}\right\}-\log |\mathbf{S}|-(p+q)
$$

dimana $p$ : jumlah peubah indikator $x, q$ : jumlah peubah indikator $y$, dan dalam penelitian ini $p=17$ dan $q=7$. $\hat{\boldsymbol{\Sigma}}$ : matriks koragam MPS dan $\mathbf{S}:$ matriks koragan contoh bagi peubah pengamatan contoh $z=\left(y^{\prime}, x^{\prime}\right)$. Misalkan $\bar{z}=\left(\bar{y}^{\prime}, \bar{x}^{\prime}\right)^{\prime}$ merupakan vektor nilai tengah contoh, maka koragam contohnya adalah

$$
\mathbf{S}=\frac{1}{n-1} \sum_{a-1}^{n}(z-\bar{z})(z-\bar{z})^{\prime}
$$

dengan $n$ : jumlah pengamatan contoh, (Bolen [5]).

Validitas dan reliabilitas peubah indikator diperoleh melalui koefisien reliabilitas indikator menggunakan rumusan berikut

$$
\rho_{i}=\frac{\left(\sum_{i=1}^{k} \lambda_{i}\right)^{2}}{\left(\sum_{i=1}^{k} \lambda_{i}\right)^{2}+\operatorname{Var}\left(\varepsilon_{i}\right)}
$$

dan reliabilitas peubah laten diperoleh melalui koefisien riliabilitas konstruk menggunakan rumusan berikut 


$$
\rho_{i i}=\frac{\left(\sum_{i=1}^{k} \lambda_{i}\right)^{2}}{\left(\sum_{i=1}^{k} \lambda_{i}\right)^{2}+\sum_{i=1}^{k}\left(1-\lambda_{i}\right)}
$$

dengan $\lambda_{i}$ : muatan faktor (peubah laten) yang terstandardisasi, (Whidiarso, [8]). Besarnya nilai koefisien relibialitas indikator (item) yang direkomendasikan adalah diatas 0,5, dan koefisien relibialitas konstruk (peubah laten) yang direkomendasikan adalah diatas 0,7, (Whidiarso [8] dan Hairet [4]).

Kesesuaian model MPS diperiksa dengan uji $\chi^{2}$ (Chi-Square Statistic), AGFI (Adjusted Goodness of Fit Index), GFI (Goodness of Fit Index) dan RMSEA (Root Mean Square Error of Approximation). Nilai $\chi^{2}$ merupakan ukuran kebaikan atau keburukan model pada data. Nilai $\chi^{2}$ dengan $p$-value $>0.05$ menunjukan model sudah baik. Nilai GFI dan AGFI yang baik adalah lebih besar dari 0.90, dengan kata lain model yang dibuat sudah sesuai, dan nilai GFI ataupun AGFI maksimum adalah 1, (Bolen). Nilai $R M S E A \leq 0.08$ memberikan indikasi bahwa model mendekati pemenuhan model terbaik, (Fox, [3]). Selain pengujian terhadap model yang dibuat, terdapat pula pengujian untuk dugaan parameter model apakah secara statistik signifikan berbeda dengan nol, pada taraf nyata $95 \%$ atau $99 \%$. Uji ini sering disebut dengan uji-t, (Bolen). Paket perangkat lunak komputer yang digunakan untuk mengoperasikan MPS dalam penelitian ini adalah Linear Structural Relationship (LISREL). LISREL mengestimasi koefisien-koefisien dari sejumlah persamaan struktural yang linear, (Jöreskog, [6]).

\subsection{Sumber dan Dekripsi Data}

Survei dalam penelitian ini dilakukan di wilayah Kota Palembang dan Kabupaten Ogan Ilir Provinsi Sumatera Selatan. Proses pengumpulan data melalui kuesioner dengan responden adalah konsumen pasar swalayan. Pemilihan responden dilakukan berdasarkan pertimbangan peneliti yang cukup mengetahui lokasi dan masalah-masalah yang khas.

Kota Palembang dan Kabupaten Ogan Ilir masing-masing memiliki 16 kecamatan sebagai klaster. Secara acak terpilih sepuluh klaster sebagai contoh. Untuk Kota Palembang terpilih Kecamatan Mir Barat, Kalidoni, Plaju, Seberang Ulu 1 dan Seberang Ulu 2. Untuk Kabupaten Ogan Mir terpilih Kecamatan Inderalaya, Inderalaya Utara, Inderalaya Selatan, Payaraman dan Tanjung Batu.

Dari setiap kecamatan yang terpilih diambil secara acak proporsional pasar swalayan yang menjadi contoh.Koesioner disebarkan kepada konsumen yang berbelanja di pasar swalayan dengan menggunakan metode sampling purposive. Pengambilan data dilakukan pada bulan November sampai Desember 2013. Terjaring sebanyak 200 responden yang mengisi dengan baik pertanyaanpertanyaan dalam koesioner. Berdasarkan jenis kelamin, responden terdiri atas $60,0 \%$ perempuan dan sisanya laki-laki. Berdasarkan kriteria kelompok umur, terdapat 17,5\% berumur kurang dari 18 tahun, 35\% antara 18 sampai 30 tahun dan sisanya diatas 30 tahun. Berdasarkan kriteria pekerjaan, terdapat $27,5 \%$ pegawai swasta, $15 \%$ pegawai negeri, $22,5 \%$ wiraswasta, $17,5 \%$ mahasiswa dan $17,5 \%$ pekerjaan lainnya. Berdasarkan kriteria frekuensi berbelanja, terdapat 32,5\% belanja satu kali seminggu, $31,5 \%$ dua kali seminggu, $21 \%$ tiga kali seminggu, dan $15 \%$ lebih dari tiga kali seminggu.

\subsection{Nilai Peubah Indikator}

Peubah-peubah indikator dilambangkan oleh $y_{1}, \ldots, y_{7}$, serta $x_{1}, \ldots, x_{17}$ untuk setiap responden. Selanjutnya, dibentuk matriks korelasi dari ke-24 peubah indikator tersebut, untuk input dalam menduga parameter model faktor konfirmatori pada persamaan (2) dan (3), dan untuk menduga parameter model MPS pada persamaan (1) secara simultan. 
Dari analisis faktor konfirmatori diperoleh hasil bahwa peubah laten Kualitas produk hanya dibentuk oleh peubah indikator $x_{1}, x_{2}$, dan $x_{5}$, peubah laten Kualitas harga dibentuk oleh peubah indikator $x_{6}, x_{7}$, dan $x_{9}$, peubah laten Kualitas karyawan dibentuk oleh $x_{11}, x_{12}$ dan $x_{14}$, peubah laten Lokasi dibentuk oleh $x_{15}, x_{16}$ dan $x_{17}$, peubah laten Kepuasan dibentuk oleh peubah indikator $y_{1}, y_{3}$ dan $y_{4}$, serta peubah laten Loyalitas dibentuk oleh peubah indikator $y_{6}$ dan $y_{7}$.

\subsection{Analisis Model MPS}

Hasil dugaan parameter model lengkap dari MPS dapat dilihat pada Gambar 2. Pengolahannya dibantu oleh program LISREL 8.50 melalui matriks korelasi yang telah dibuat sebelumnya, dengan menggunakan metode $M L$.

Model terdiri atas model pengukuran dan model jalur, dengan empat peubah laten eksogen yaitu Kualitas produk, Kualitas harga, Kualitas karyawan dan Kualitas lokasi, serta dua peubah laten endogen yaitu Kepuasan dan Loyalitas konsumen. Diperoleh nilai Chi-square dengan derajat bebas 104 sebesar 127,00, dan P-value bernilai 0,06511 lebih besar dari 0.05. Nilai RMSEA sebesar 0.074 lebih kecil dari 0.08, serta nilai GFI sebesar 0,90 dan AGFI sebesar 0.91 keduanya lebih besar dari dari 0.90 , ini berarti bahwa model yang dibuat telah dapat mewakili dengan baik hubungan yang terdapat pada data contoh, atau model dapat dikatakan sudah baik.

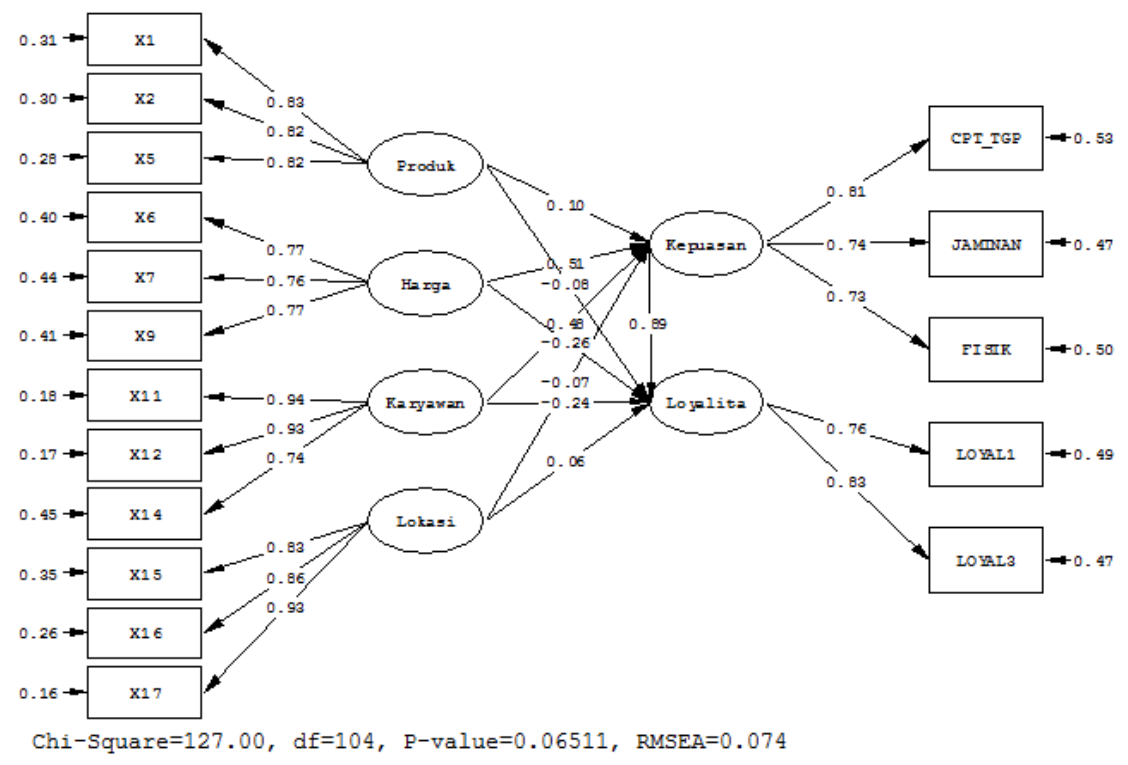

Gambar 2. Model Struktural MPS lengkap

Dugaan koefisien model pengukuran beserta nilai statistik uji- $t$ nya, serta tanda signifikansinya dalam bentuk bintang, tersusun pada Tabel 2 .

Pada Tabel 2 terlihat bahwa semua koefisien model pengukuran signifikan pada taraf $1 \%$, dengan nilai $t$ pada tabel adalah 2,576, sehingga dapat dikatakan bahwa peubah-peubah indikator sudah valid.Model yang terbentuk juga telah reliabel, berdasarkan nilai-nilai koefisien reliabilitas indikatoryang semuanya lebih besar dari 0,5, dan koefisien reliabilitas konstruk yang semuanya lebih besar dari 0,7, yang diperoleh dari persamaan (5) dan persaman (6). Secara ringkas nilai koefisien reliabilitas dapat dilihat pada Tabel 3. 
Tabel 2. Nilai dugaan parameter model pengukuran

\begin{tabular}{|c|c|c|c|c|c|c|}
\hline \multicolumn{3}{|c|}{ model pengukuran } & \multirow{2}{*}{ Peubah laten } & \multirow{2}{*}{$\begin{array}{c}\text { Simbol } \\
\text { peubah } \\
\text { indikator }\end{array}$} & \multirow{2}{*}{$\begin{array}{c}\text { Koefisien } \\
\text { Reliabilitas } \\
\text { indikator } \\
\end{array}$} & \multirow{2}{*}{$\begin{array}{c}\text { Koefisien } \\
\text { Reliabilitas } \\
\text { konstruk } \\
\end{array}$} \\
\hline Parameter Model pengukuran & Nilai dugaan & $t$-value & & & & \\
\hline$\lambda_{1,1}^{x}$ & 0.83 & $13,62^{\star * *}$ & \multirow{3}{*}{$\begin{array}{l}\text { Kualitas } \\
\text { Produk } \\
\left(\xi_{1}\right)\end{array}$} & $x_{1}$ & 0,69 & \multirow{3}{*}{0,86} \\
\hline$\lambda_{2,1}^{x}$ & 0.82 & $13,61^{* *}$ & & $x_{2}$ & 0,67 & \\
\hline$\lambda_{5,1}^{x}$ & 0.82 & $13,60^{\star * *}$ & & $x_{5}$ & 0,67 & \\
\hline$\lambda_{6,2}^{x}$ & 0.77 & $11,46^{\star *}$ & \multirow{3}{*}{$\begin{array}{c}\text { Kualitas } \\
\text { Harga } \\
\left(\xi_{2}\right)\end{array}$} & $x_{6}$ & 0,59 & \multirow{3}{*}{0,81} \\
\hline$\lambda_{7,2}^{x}$ & 0.76 & $11,34^{* *}$ & & $x_{7}$ & 0,58 & \\
\hline$\lambda_{9,2}^{x}$ & 0.77 & $11,41^{* *}$ & & $x_{9}$ & 0,59 & \\
\hline$\lambda_{11,3}^{x}$ & 0.94 & $16,43^{* *}$ & \multirow{3}{*}{$\begin{array}{l}\text { Kualitas } \\
\text { Karyawan } \\
\left(\xi_{3}\right)\end{array}$} & $x_{11}$ & 0,88 & \multirow{3}{*}{0,91} \\
\hline$\lambda_{12,3}^{x}$ & 0.93 & $16,26^{* *}$ & & $x_{12}$ & 0,86 & \\
\hline$\lambda_{14,3}^{x}$ & 0.74 & $11,87^{* *}$ & & $x_{14}$ & 0,55 & \\
\hline$\lambda_{15,4}^{x}$ & 0,83 & $13,63^{* *}$ & \multirow{3}{*}{$\begin{array}{l}\text { Kualitas } \\
\text { Lokasi } \\
\left(\xi_{4}\right)\end{array}$} & $x_{15}$ & 0,69 & \multirow{3}{*}{0,81} \\
\hline$\lambda_{16,4}^{x}$ & 0,86 & $14,12^{\star *}$ & & $x_{16}$ & 0,74 & \\
\hline$\lambda_{17,4}^{x}$ & 0,93 & $16,28^{* *}$ & & $x_{17}$ & 0,86 & \\
\hline$\lambda_{2,1}^{y}$ & 0.81 & - & \multirow{3}{*}{$\begin{array}{l}\text { Kepuasan } \\
\text { Konsumen } \\
\left(\eta_{1}\right)\end{array}$} & $y_{2}$ & 0,66 & \multirow{3}{*}{0,80} \\
\hline$\lambda_{3,1}^{y}$ & 0.74 & $8,05^{* *}$ & & $y_{3}$ & 0,55 & \\
\hline$\lambda_{41}^{y}$ & 0.73 & $7,84^{* *}$ & & $y_{4}$ & 0,53 & \\
\hline$\lambda_{\rho}^{y}$ & 0.76 & - & \multirow{2}{*}{$\begin{array}{c}\text { Loyalitas } \\
\text { Konsume } \\
\left(\eta_{2}\right)\end{array}$} & $y_{6}$ & 0,58 & \multirow{2}{*}{0,78} \\
\hline$\lambda^{y}$ & 083 & $590 * *$ & & $y_{7}$ & 0,69 & \\
\hline
\end{tabular}

**) signifikan pada taraf $1 \%$
Tabel 3. Nilai koefisien reliabilitas

\section{Dugaan koefisien model jalur beserta nilai statistik uji-t nya, serta tanda signifikansinya dalam bentuk bintang, tersusun pada Tabel 4.}

Tabel 4. Nilai dugaan parameter model jalur

\begin{tabular}{ccc}
\hline $\begin{array}{c}\text { Parameter } \\
\text { Model Jalur }\end{array}$ & $\begin{array}{c}\text { Nilai } \\
\text { dugaan }\end{array}$ & $t$-value \\
\hline$\beta_{2,1}$ & 0,89 & $3,31^{* *}$ \\
\hline$\gamma_{1,1}$ & 0,10 & 1,22 \\
\hline$\gamma_{1,2}$ & 0,51 & $5,91^{* *}$ \\
\hline$\gamma_{1,3}$ & 0,48 & $5,50^{* *}$ \\
\hline$\gamma_{1,4}$ & $-0,07$ & $-0,84$ \\
\hline$\gamma_{2,1}$ & -0.08 & $-0,83$ \\
\hline$\gamma_{2,2}$ & -0.26 & $-1,67$ \\
\hline$\gamma_{2,3}$ & $-0,24$ & $-1,61$ \\
\hline$\gamma_{2,4}$ & 0.06 & 0,62 \\
\hline
\end{tabular}


Pada tabel 4, terdapat tiga parameter koefisien model jalur yang signifikan pada taraf $1 \%$ yaitu $\gamma_{1,2}$, $\gamma_{1,3}$ dan $\beta_{2,1}$. Tabel 4 juga menunjukan besarnya pengaruh langsung dari ke empat buah peubah laten eksogen terhadap kedua buah peubah laten endogen. Dapat dijelaskan bahwa, peubah-peubah laten Kualitas harga dan Kualitas karyawan memberikan pengaruh langsung secara signifikan terhadap peubah laten Kepuasan konsumen sebesar 0,51 dan 0,48 dengan nilai statistik uji- $t$ nya masing-masing 5,91 dan 5,50, artinya peningkatan faktor kualitas harga satu satuan, secara langsung dapat menaikkan 0.51 satuan kepuasan konsumen pasar swalayan, dan peningkatan faktor kualitas karyawan satu satuan, secara langsung dapat menaikkan 0.48 satuan kepuasan konsumen pasar swalayan. Namun tidak ada satupun peubah laten eksogen yang berpengaruh langsung secara signifikan terhadap peubah laten Loyalitas konsumen. Artinya, faktor kualitas produk, kualitas harga, kualitas karyawan dan lokasi tidak ada yang secara siginifikan berpengaruh langsung terhadap loyalitas konsumen. Selanjutnya peubah laten Kepuasan memberikan pengarung langsung terbesar terhadap peubah laten Loyalitas konsumen sebesar 0,89 dengan nilai statistik uji- $t$ nya sebesar 3,31, artinya peningkatan faktor kualitas konsumen satu satuan, secara langsung dapat menaikkan 0,89 satuan loyalitas konsumen pasar swalayan.

Selain pengaruh langsung, terdapat pengaruh tidak langsung dari keempat peubah laten eksogen terhadap peubah laten endogen Loyalitas, yang diperoleh melalui perkalian nilai koefisien langsung antara peubah yang terlibat. Pengaruh tidak langsung secara signifikan diberikan oleh peubah Kualitas harga terhadap peubah laten Loyalitas melalui peubah antara yaitu peubah laten Kepuasan konsumensebesar 0,45 dengan nilai statistik uji-t nya sebesar 3,12,dan peubah Kualitas karyawanterhadap peubah laten Loyalitas melalui peubah antara yaitu peubah laten Kepuasan konsumensebesar 0,43 dengan nilai statistik uji-t nya sebesar 2,88.

Pengaruh total peubah-peubah laten eksogen terhadap kepuasan konsumen, yang merupakan penjumlahan pengaruh langsung dan tidak langsung dari setiap peubah laten eksogen terhadap peubah laten endogen, paling besar diberikan oleh peubah laten Kualitas harga sebesar 0,19 dengan nilai statistik uji- $t$ nya sebesar 2,23. Sedangkan Pengaruh total paling besar terhadap peubah laten Loyalitas konsumen secara signifikan diberikan oleh peubah laten Kepuasan sebesar 0,89 dengan nilai statistik uji- $t$ nya sebesar 3,31.

Berdasarkan hasil MPS pada penelitian ini maka untuk meningkatkan daya saing pasar swalayan, dan menjadi pilihan masyarakat dalam berbelanja, yang utama adalah perlu memperhatikan kepuasan konsumen, yaitu dengan meningkatkan kualitas harga dan kualitas karyawan. Harga yang lebih ekonomis dengan kualitas produk yang sama dibandingkan pasar swalayan lain, akan lebih menarik minat konsumen, terlebih jika ditambah adanya diskon pada beberapa produk yang paling dibutuhkan pembeli. Kemudahan dalam melakukan transaksi pembayaran juga dapat menarik konsumen untuk berbelanja di pasar swalayan. Selain itu, karyawan yang ramah dan mudah berinteraksi dengan konsumen dapat memberikan energi positif pada konsumen, sehingga konsumen merasa nyaman ketika berbelanja dan akan menghabiskan waktu yang tidak sedikit untuk memilah produk bahkan membeli yang tidak direncanakannya. Kepedulian karyawan pada keluhan konsumen dan cepatnya karyawan menaggapi keluhan tersebut, akan dapat meningkatkan kepuasan konsumen yang secara langsung juga membuat konsumen menjadi loyal terhadap pasar swalayan.

\section{Simpulan}

Peubah-peubah indikator yang ada dalam model MPS valid dan reliabel membentuk keenam peubah laten Kualitas Produk, Kualitas harga, Kualitas karyawan, Kualitas Lokasi, Kepuasan dan Loyalitas. Faktor yang secara signifikan mempengaruhi kepuasan konsumen pasar swalayan adalah kualitas harga dan kualitas karyawan, pengaruhnya bersifat langsung dan positif. Faktor kepuasan konsumen menjadi pengaruh total terbesar terhadap loyalitas konsumen, pengaruhnya bersifat langsung dan positif. 


\section{Daftar Pustaka}

1. Afifuddin M. 2009. Analisis Pengaruh kualitas Pelayanan Terhadap kepuasan Pelanggan Pada PT (PERSERO) Angkasa Pura I Di Bandar Udara Ahmad Yani MPSarang. Tugas Akhir Program Magister, http://www. pdfbe.com/b0/b048b8805d2ed362-download.pdf, diakses tanggal 28 Maret 2011.

2. Bollen K. A. 1989. Structural Equation with Laten Variables. John Wiley. New York.

3. Fox J. 2002. Structural Equation Models. www.ppsw.rug.nl/ boomsma/ csaref.pdf. Diakses tanggal: 1 Agustus 2005

4. Hair et. al. 1998. Multivariate Data Analysisi Englewood Cliffs. New Jersey. Prentice Hall.

5. Harun H. 2006. Analisis Faktor-faktor yang Mempengaruhi Kepuasan Pelanggan Untuk meningkatkan Loyaitas Pelanggan Produk Telkomsel Fleksi. Tesis. Universitas Dipenogoro, http://www.pdfbe. Com/haidir_harun.pdf, diakses tangga: 23 Maret 2011

6. Jöreskog K. G. and Sörbom, D. 1996. Lisrel 8: User's Reference Guide. Scientific Software International, Inc. Chicago.

7. Sutanto AJ. 2008. Pengaruh Service Quality dan Perceive Value terhadap Kepuasan dan Loyalitas Konsumen Appartemen di kota Surabaya. Majalah Ekonomi. Tahun XVIII, No.3. Hal. 286-301.

8. Whidiarso W. 2011. Reliabilitas dan Validitas dalam Pemodelan Persamaan Struktural SEM. Fakultas Psikologi Universitas gadjah Mada.

9. Zeithaml AV. Parasuraman A and Berry LL. 1990. Delivering Quality Service, Balancing Customer Perception and Expectations. The Free Press. New York. 
Dwipurwani and Eliyati/ JMI Volume 10 No 2, Oktober 2014, pp 107-115 